\title{
Cognitive functioning and functional brain networks in postoperative WHO grade I meningioma patients
}

\author{
David van Nieuwenhuizen ${ }^{1,6,7}$ (1) Linda Douw ${ }^{4,6} \cdot$ Martin Klein $^{2,6} \cdot$ Saskia M. Peerdeman ${ }^{5,6} \cdot$ Jan J. Heimans ${ }^{1,6}$. \\ Jaap C. Reijneveld ${ }^{1,6} \cdot$ Cornelis J. Stam $^{3} \cdot$ Arjan Hillebrand $^{3}$
}

Received: 16 July 2018 / Accepted: 21 August 2018 / Published online: 15 September 2018

(c) The Author(s) 2018

\begin{abstract}
Introduction Meningioma patients often have subtle cognitive deficits that might be attributed to the tumor itself, to surgical treatment, or to the occurrence of seizures and their treatment. Magnetoencephalography (MEG) analysis of resting-state functional networks (RSNs) could help to understand the neurophysiological basis of cognitive impairment in these patients. We explored the correlation between RSN functional connectivity and topology of functional networks on the one hand, and cognition on the other hand in WHO grade I meningioma patients.

Methods Twenty adult WHO grade I meningioma patients who had undergone tumor resection, as well as 20 healthy matched controls, were included. Neuropsychological assessment was done through a standardized test battery. MEG data were recorded, and projected to the anatomical space of the Automated Anatomical Labeling atlas. Functional connectivity (PLI), within the default mode network (DMN) and the bilateral frontoparietal networks were correlated to cognitive performance. Minimum spanning tree (MST) characteristics were correlated with cognitive functioning.

Results Compared to healthy controls, meningioma patients had lower working memory capacity $(p=0.037)$. Within the patient group, lower working memory performance was associated with lower DMN connectivity and a lower maximum MST degree in the theta band (resp. $p=0.044$ and $p=0.003$ ).

Conclusions This study shows that cognitive functioning is correlated with functional connectivity in the default mode network and hub-pathology in WHO grade I meningioma patients. Future longitudinal studies are needed to corroborate these findings and to further investigate the pathophysiology of cognitive deficits and possible changes in functional brain networks in meningioma patients.
\end{abstract}

Keywords Cognitive functioning $\cdot$ Functional connectivity $\cdot$ Magnetoencephalography $\cdot$ Resting-state networks · Meningioma $\cdot$ Minimum spanning tree

$\begin{array}{ll}\text { Abbreviations } \\ \text { RSN } & \text { Resting-state network } \\ \text { PLI } & \text { Phase lag index } \\ \text { DMN } & \text { Default mode network } \\ \text { FPN } & \text { Frontoparietal network }\end{array}$

Electronic supplementary material The online version of this article (https://doi.org/10.1007/s11060-018-2987-1) contains supplementary material, which is available to authorized users.

David van Nieuwenhuizen

DvanNieuwenhuizen@amphia.nl

1 Department of Neurology, Amsterdam University Medical Centers, Location VUmc, Amsterdam, The Netherlands

2 Department of Medical Psychology, Amsterdam University Medical Centers, Location VUmc, Amsterdam, The Netherlands

3 Department of Clinical Neurophysiology and MEG Center, Amsterdam University Medical Centers, Location VUmc, Amsterdam, The Netherlands
4 Department of Anatomy and Neurosciences, Amsterdam University Medical Centers, Location VUmc, Amsterdam, The Netherlands

5 Department of Neurosurgery, Amsterdam University Medical Centers, Location VUmc, Amsterdam, The Netherlands

6 Brain Tumor Center Amsterdam, Amsterdam University Medical Centers, Location VUmc, Amsterdam, The Netherlands

7 Department of Neurology, Amphia Hospital, Molengracht 21, 4818 CK Breda, The Netherlands 


$\begin{array}{ll}\text { MEG } & \text { Magnetoencephalography } \\ \text { EEG } & \text { Electroencephalography } \\ \text { fMRI } & \text { Functional magnetic resonance imaging } \\ \text { BOLD } & \text { Blood-oxygenation-level-dependent } \\ \text { CNS } & \text { Central nervous system } \\ \text { AAL } & \text { Automated Anatomical Labeling } \\ \text { MST } & \text { Minimum spanning tree }\end{array}$

\section{Introduction}

Meningiomas are the most frequently diagnosed primary CNS tumors. Ninety percent of meningiomas are WHO grade I tumors, and have a relatively benign disease course [1]. Notwithstanding this favorable prognosis, many WHO grade I meningioma patients show subtle cognitive impairments that affect health-related quality of life [2]. Cognitive impairments may be due to the tumor, peritumoral edema, surgical treatment, or the occurrence of seizures and their treatment with anti-epileptic drugs.

Cognitive deficits in brain tumor patients tend to be global and cannot be explained unequivocally by local damage alone [3]. It has become clear in recent years that the brain is a complex network of interacting brain regions, and that an optimal organization of functional brain networks is required for adequate cognitive functioning $[4,5]$. Brain tumors lead to global alterations in functional interactions, even between brain regions remote from the tumor [6-8]. This insight has increased our understanding of the symptoms in these patients: the severity of cognitive symptoms may be explained by alterations of specific networks, possibly depending on pathophysiology and growth pattern [9].

Functional brain networks can be reconstructed using magnetoencephalography (MEG), electroencephalography (EEG) or functional magnetic resonance imaging (fMRI). Using MEG, it has been shown that glioma patients have globally disturbed brain network organization during the resting-state [3, 6-12]. Increased whole-brain functional connectivity in the delta, theta and gamma frequency bands has been associated with poorer cognitive performance in glioma patients, and global network properties such as clustering and path length also relate to patients' cognitive status [10-12]. However, meningiomas differ from gliomas in many aspects: meningiomas are extra-axial, usually slow growing tumors, whereas gliomas are infiltrative, and very often fast growing intra-axial tumors. It is as yet unclear if and how functional networks are affected by meningiomas. Previous studies have shown that high cost/high value hubs of human brain networks are more likely to be anatomically abnormal than non-hubs in many (if not all) brain disorders, suggesting that hub-damage may be associated with clinically significant cognitive impairments [13].
Studies have shown that the functional brain network is composed of several sub-networks, known as restingstate networks (RSNs), and these RSNs have been linked to cognitive functioning $[14,15]$. The default mode network (DMN), which is mostly deactivated during tasks, is the most consistently described RSN, and its resting-state activity has been related to performance in several cognitive domains, including attention and working memory, in both health and disease [16]. Left-sided and right-sided frontoparietal networks (FPN) are crucial for attention, language and memory processing [15]. Correlations between decreased RSN activity and cognitive deficits have been described in several neurological disorders, such as dementia, stroke, and epilepsy [16-18]. In the majority of studies that have investigated RSNs and their associations with cognition, fMRI has been used. MEG provides a direct measure of neuronal activity with high temporal resolution, making it an excellent non-invasive technique for the characterization of functional brain networks [19]. The RSNs that are typically observed in fMRI have been replicated in MEG [20].

Rather than focusing on specific sub-networks, the topology of the functional network as a whole can also be characterized using graph theoretical tools. Although conventional graph theoretical analyses are helpful in understanding disease mechanisms [4, 5], there are methodological difficulties that may hamper interpretation of results [21]; graph measures are influenced by the size of the network (i.e. the number of nodes), network sparsity (percentage links present), and the average degree (i.e. the number of connections per node). The minimum spanning tree (MST), on the contrary, is a unique reconstruction of the backbone of the functional network, provided that all the weights are unique [22]. Recent studies have shown that MST network analyses are able to detect network changes within patient groups (e.g. [23, 24]).

Here, we explored the correlations between band-specific connectivity within three MEG RSNs and the MST on the one hand, and cognitive functioning on the other hand in WHO grade I meningioma patients. We hypothesized that lower network connectivity in meningioma WHO grade I patients is related to poorer cognitive performance. Furthermore, we investigated whether we could detect correlations between the topology of functional networks and cognitive functioning.

\section{Methods}

\section{Patients}

Consecutive adult WHO grade I meningioma patients who had undergone tumor resection, without adjuvant treatment, were assessed. 
Excluded from the study were patients with atypical or malignant meningioma (WHO grade II or III), as well as patients who suffered from one of the following medical conditions that may interfere with normal cognitive functioning: other central nervous system (CNS) or non-CNS malignancy, cerebrovascular pathology, congenital CNS malformations, multiple sclerosis, Parkinson's disease, organic psychosis, dementia, or schizophrenia. Furthermore, patients had to have sufficient proficiency of the Dutch language to be able to carry out the cognitive tests.

\section{Healthy controls}

Healthy controls providing normative data for cognitive functioning were selected from the Maastricht Aging Study, which comprises a cross-sectional study into the biomedical and psychological determinants of cognitive aging of 2000 healthy individuals aged 24-81 years [25]. Patients and healthy controls were individually matched with respect to sex, age, and educational level. Educational level was assessed by a Dutch scoring system consisting of an eightpoint scale, ranging from unfinished primary education (level 1) to university level (level 8) [26].

\section{Ethics statement}

Ethical approval was granted by the VU University Medical Ethics Committee. All patients gave written informed consent before participating. All clinical investigations were conducted according to the Declaration of Helsinki.

\section{Neuropsychological assessment}

A wide range of cognitive functions was assessed by means of a standardized test battery (Appendix 1). The total time required to complete the battery was approximately $60 \mathrm{~min}$. Individual cognitive test scores were converted into z-scores using the means and standard deviations (SDs) of the scores for the age-, sex-, and education-matched healthy controls as a reference. Subsequently, z-scores were transformed into the following six cognitive domains: executive functioning, working memory, verbal memory, attention, information processing speed, and psychomotor speed [27]. Cognitive dysfunction was defined as a $\mathrm{z}$-score $\geq 1.5 \mathrm{SD}$ below the mean for the healthy controls.

\section{Magnetoencephalography (MEG)}

Postoperative MEG recordings were made in a magnetically shielded room (VacuumSchmelze GmbH, Hanua, Germany) using a 151-channel whole-head MEG system (CTF Systems Inc., Port Coquitlam, BC, Canada). Approximately 5 min of MEG data were recorded with a third-order software gradient, a sample frequency of $625 \mathrm{~Hz}$ and a passband of $0-100 \mathrm{~Hz}$.

At the start and end of the measurement, the head position relative to the coordinate system of the helmet was determined by leading small currents through three headposition coils situated at the left and right pre-auricular points and the nasion. Changes in head position smaller than $0.5 \mathrm{~cm}$ during the recording were accepted. The MEG recordings were performed in a no task, eyes-closed and eyes-open resting state condition, followed by the delayed non-matching-to-sample (DNMTS) task [28]. Only data from the eyes-closed condition were analysed here. For each participant, the continuous approximately $5 \mathrm{~min}$ long resting-state, eyes-closed recording was divided into epochs of $6.555 \mathrm{~s}$. Channels and epochs were visually inspected for representing an alert eyes-closed state. Epochs or channels were rejected when containing system related or physiological artefacts or too much environmental noise, leading to discarding of on average 6.3 channels (range 3-10). On average 35.3 epochs (range 25-47) were selected and subsequently projected to source-space (see below).

\section{Anatomical MRI}

Postoperative structural magnetic resonance images (MRIs) were used for co-registration [29], and the outline of the scalp as obtained from the co-registered MRI was used as a multi-sphere headmodel [30]. The co-registered MRI was then spatially normalized to a template MRI using the SEG toolbox in SPM8. The Automated Anatomical Labeling (AAL) atlas was used to label the voxels in a subject's normalized co-registered MRI. Subcortical structures were removed, and the voxels in the remaining 78 cortical regions of interest (ROIs) were used for further analyses, after inverse transformation to the patient's co-registered MRI.

\section{Time series estimation for regions-of-interest}

We used the beamformer approach [29] as described by Hillebrand et al. [31], which reconstructs a single time series of neuronal activity for each ROI and frequency band separately. For the beamformer computations we used the data covariance for, on average, $231 \mathrm{~s}$ (range 164-308 s) of data, and used a unity matrix for the noise covariance. Three frequency bands were analyzed: theta $(4-8 \mathrm{~Hz})$, lower alpha $(8-10 \mathrm{~Hz})$, and upper alpha $(10-13 \mathrm{~Hz})$. Five artefact free epochs of 4096 samples $(6.555 \mathrm{~s})$ were subsequently selected $[\mathrm{DvN}]$ and analyzed using Brainwave v0.9.58 [authored by C.S.; available at http://home.kpn.nl/stam7883/brainwave. html]. 


\section{Functional connectivity}

The phase lag index (PLI) was used to assess functional connectivity between the reconstructed source-space signals. The PLI is a measure that is relatively insensitive to the effects of volume conduction and field spread [32]. For each subject, the PLI was calculated for all possible ROI pairs. The functional connectivity within one of the predefined RSNs described below was then computed by averaging all PLI values between the ROIs within that sub-network.

\section{Resting-state networks}

We defined MEG RSNs by selecting only those connections between the ROIs within literature-based RSNs [15]. We selected three RSNs that are of interest for cognitive functioning in the domains that are frequently affected in meningioma patients, namely the default mode network (DMN), and the left and the right frontoparietal network (FPN) (see Table S1 for included ROIs) [2]. Only if the meningioma patients differed from healthy controls regarding cognitive functioning, we investigated associations between the significantly different cognitive domain(s) and average functional connectivity within these three RSNs.

\section{Minimum spanning tree analyses}

The minimum spanning tree of an undirected weighted graph is a unique subgraph that connects all the nodes in such a way that the total cost (the sum of all the edge distances) is minimized without forming cycles. For each subject, each epoch, and each frequency band separately, we constructed the MST based on the PLI adjacency matrix by applying Kruskal's algorithm [23, 33]. Subsequently we characterized the topology of the MST using the following global metrics: maximum degree, leaf fraction, mean eccentricity, maximum betweenness centrality (BC), and tree hierarchy $\left(T_{H}\right)[23,33,34]$. These metrics were averaged over epochs for each subject and frequency bands.

\section{Statistics}

Because of the non-normal distribution of the data and small sample size, Mann-Whitney $U$ tests were used to test for differences in cognitive functioning between patients and healthy controls. Furthermore, Kendall's Tau coefficients (two-tailed) were used to determine the associations between cognitive functioning and the mean PLI within each RSN and global MST metrics. In the statistical analyses performed using SPSS (version 20.0 for Windows) statistical significance was set at $p<0.05$.

\section{Results}

\section{Sociodemographic and clinical characteristics}

Of the 38 patients who met the inclusion criteria, 18 patients were excluded; of these 18, 10 declined participation as they expected testing to be too burdensome. In the remaining 8 patients, either MRI or MEG could not be used for analysis due to artefacts. No significant differences for age, sex, and educational level were found between the included and excluded patients. Mean time between resection and testing (MEG and neuropsychological assessment) was 1.7 years (range 0.4-4.6 years). As a result of the matching procedure, the 20 remaining patients and healthy controls did not differ in age, sex, or educational level (Table 1).

\section{Cognitive functioning}

Patients had significantly lower working memory capacity (Mann-Whitney $\mathrm{U}=268.000, p=0.037$ ) compared to healthy controls. No statistically significant differences were found between patients and healthy controls in executive functioning, verbal memory, attention functioning, information processing speed, or psychomotor speed (Table 2).

\section{Associations between functional connectivity and working memory}

Correlational analyses (Kendall's tau) showed significant positive associations between theta band DMN connectivity and working memory $(r=0.326 ; p=0.044)$. No significant associations were found between working memory capacity and connectivity in the other RSNs, nor for other frequency bands. Furthermore, working memory z-scores also correlated positively with the MST maximum degree in the theta band $(r=0.503 ; p=0.003)$. No significant associations were found between working memory scores and other MST metrics, nor for other frequency bands (Table 3). Post hoc analyses showed no significant associations between average functional connectivity of the global network and cognitive functioning (Table 4).

\section{Discussion}

In this MEG study we found that postoperative WHO grade I meningioma patients had cognitive deficits in the working memory domain. This decrease in working memory performance was associated with lower functional connectivity 
Table 1 Patients' sociodemographic and clinical characteristics
Table 2 Cognitive functioning in meningioma patients compared to healthy controls

\begin{tabular}{|c|c|c|c|}
\hline & \multirow{2}{*}{$\begin{array}{l}\text { Meningioma patients } \\
(n=20) \\
\text { Mean }\end{array}$} & \multicolumn{2}{|c|}{ Healthy controls $(n=20)$} \\
\hline & & Mean & $\mathrm{P}^{*}$ \\
\hline \multicolumn{4}{|l|}{ Characteristics } \\
\hline Mean age in years ${ }^{\mathrm{a}}$ & $51.4(10.9)$ & $51.6(11.0)$ & 0.99 \\
\hline Sex, \# males $(\%)$ & $6(30.0)$ & $6(30.0)$ & \\
\hline Educational level (median and range) $^{\mathrm{b}}$ & $4(6)$ & $4(6)$ & 1.0 \\
\hline \multicolumn{4}{|l|}{ Premorbid intelligence } \\
\hline Dutch adult reading test (raw scores) & $88.3(11.3)$ & $\mathrm{n} / \mathrm{a}$ & \\
\hline Time between resection and testing (years*) & $1.7(0.4-4.6)$ & $\mathrm{n} / \mathrm{a}$ & \\
\hline \multicolumn{4}{|l|}{ Functional/performance status } \\
\hline Barthel & $19.8(0.8)$ & $\mathrm{n} / \mathrm{a}$ & \\
\hline \multicolumn{4}{|l|}{ Location of tumor (\#) } \\
\hline Frontal & 12 & & \\
\hline Parietal & 4 & & \\
\hline Temporal & 2 & & \\
\hline Occipital & 2 & & \\
\hline
\end{tabular}

Data are mean and standard deviation (given between brackets), unless indicated otherwise n/a Not applicable or not available; \# number

* Mean years (and range) since tumor resection and neurocognitive testing

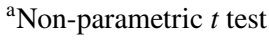

\begin{tabular}{lllll}
\hline Cognitive domain & $\begin{array}{l}\text { Meningioma patients } \\
\mathrm{N}=20\end{array}$ & $\begin{array}{l}\text { Healthy controls } \\
\mathrm{N}=20\end{array}$ & $P^{*}$ & Mann-Whitney U \\
\hline Executive functioning & $-0.0960(1.011)$ & $0.0312(0.760)$ & 0.477 & 178.000 \\
Psychomotor speed & $-0.2921(0.981)$ & $0.0243(0.730)$ & 0.159 & 237.000 \\
Working memory & $-0.5348(1.004)$ & $0.0127(0.8970)$ & $\mathbf{0 . 0 3 7}$ & 268.000 \\
Information processing & $-0.3352(1.130)$ & $0.0176(0.992)$ & 0.467 & 234.500 \\
Attention & $-0.2682(1.162)$ & $0.0122(0.814)$ & 0.347 & 184.000 \\
Verbal memory & $0.1466(1.050)$ & $0.0715(0.610)$ & 0.224 & 163.000 \\
\hline
\end{tabular}

Results are mean with (standard deviation)

For the neuropsychological characteristics Z-scores derived from the mean and SD of the healthy controls are displayed

*Significantly different $(p<0.05)$ from the Meningioma patients using Mann-Whitney U-test (one-tailed) in the DMN and lower MST maximum degree in the theta band.

Previous studies have shown that pre- and postoperative meningioma patients have cognitive deficits, including in the working memory domain, in concordance with our current findings [2].

Prior to the present study, no studies had been performed on functional connectivity in WHO grade I meningioma patients. In previous studies on patients with other types of brain tumors (gliomas), associations between functional connectivity and cognitive functioning were found mainly in the theta, lower and upper alpha bands [8-10]. Other studies have revealed associations between theta band connectivity on the one hand and working memory and attention on the other hand in healthy subjects. The theta band may be especially important for working memory [35]. Therefore we focused on these frequency bands in the current work.

The DMN has mainly been described in fMRI studies as a network that is deactivated during task performance, while its resting-state level of connectivity correlates with attention and working memory performance. Decreased connectivity of the DMN has been associated with deficits in attentional control and working memory, and our results corroborate these findings [16].

In the present study, post-hoc analyses did not show significant associations between average functional connectivity of the global network and cognitive functioning. This is somewhat different from findings in previous studies in 
Table 3 Correlations between working memory and functional connectivity

\begin{tabular}{|c|c|c|c|c|c|c|c|c|}
\hline & $\begin{array}{l}\text { PLI DMN } \\
\text { Theta }\end{array}$ & $\begin{array}{l}\text { PLI FPL } \\
\text { Theta }\end{array}$ & $\begin{array}{l}\text { PLI FPR } \\
\text { Theta }\end{array}$ & $\begin{array}{l}\text { MST degree } \\
\text { Theta }\end{array}$ & $\begin{array}{l}\text { MST leaf } \\
\text { Theta }\end{array}$ & $\begin{array}{l}\text { MST eccentricity } \\
\text { Theta }\end{array}$ & $\begin{array}{l}\text { MST BC } \\
\text { Theta }\end{array}$ & $\begin{array}{l}\text { MST T } \\
\text { Theta }\end{array}$ \\
\hline \multirow[t]{2}{*}{ Working memory } & $\begin{array}{l}\mathrm{r}=0.326^{\mathrm{a}} \\
p=0.044\end{array}$ & $\begin{array}{l}\mathrm{r}=0.221^{\mathrm{a}} \\
p=0.173\end{array}$ & $\begin{array}{l}\mathrm{r}=-0.168^{\mathrm{a}} \\
p=.299\end{array}$ & $\begin{array}{l}\mathrm{r}=\mathbf{0 . 5 0 3}^{\mathrm{a}} \\
p=\mathbf{0 . 0 0 3}\end{array}$ & $\begin{array}{l}\mathrm{r}=0.117^{\mathrm{a}} \\
p=0.474\end{array}$ & $\begin{array}{l}\mathrm{r}=-0.184^{\mathrm{a}} \\
p=0.267\end{array}$ & $\begin{array}{l}\mathrm{r}=0.174^{\mathrm{a}} \\
p=0.284\end{array}$ & $\begin{array}{l}\mathrm{r}=0.084^{\mathrm{a}} \\
p=0.604\end{array}$ \\
\hline & $\begin{array}{l}\text { PLI DMN } \\
\text { Lower alpha }\end{array}$ & $\begin{array}{l}\text { PLI FPL } \\
\text { Lower alpha }\end{array}$ & $\begin{array}{l}\text { PLI FPR } \\
\text { Lower alpha }\end{array}$ & $\begin{array}{l}\text { MST degree } \\
\text { Lower alpha }\end{array}$ & $\begin{array}{l}\text { MST leaf } \\
\text { Lower alpha }\end{array}$ & $\begin{array}{l}\text { MST eccentricity } \\
\text { Lower alpha }\end{array}$ & $\begin{array}{l}\text { MST BC } \\
\text { Lower alpha }\end{array}$ & $\begin{array}{l}\text { MST T }_{H} \\
\text { Lower alpha }\end{array}$ \\
\hline \multirow[t]{2}{*}{$\begin{array}{l}\text { Working } \\
\text { memory }\end{array}$} & $\begin{array}{l}\mathrm{r}=-0.005^{\mathrm{a}} \\
p=0.974\end{array}$ & $\begin{array}{l}\mathrm{r}=0.174^{\mathrm{a}} \\
p=0.270\end{array}$ & $\begin{array}{l}\mathrm{r}=0.126^{\mathrm{a}} \\
p=0.436\end{array}$ & $\begin{array}{l}\mathrm{r}=-0.065^{\mathrm{a}} \\
p=0.695\end{array}$ & $\begin{array}{l}\mathrm{r}=0.085^{\mathrm{a}} \\
p=0.603\end{array}$ & $\begin{array}{l}\mathrm{r}=-.048^{\mathrm{a}} \\
p=0.770\end{array}$ & $\begin{array}{l}\mathrm{r}=0.274^{\mathrm{a}} \\
p=0.092\end{array}$ & $\begin{array}{l}\mathrm{r}=0.084^{\mathrm{a}} \\
p=0.604\end{array}$ \\
\hline & $\begin{array}{l}\text { PLI DMN Upper } \\
\text { alpha }\end{array}$ & $\begin{array}{l}\text { PLI FPL } \\
\text { Upper alpha }\end{array}$ & $\begin{array}{l}\text { PLI FPR } \\
\text { Upper alpha }\end{array}$ & $\begin{array}{l}\text { MST degree } \\
\text { Upper alpha }\end{array}$ & $\begin{array}{l}\text { MST leaf } \\
\text { Upper alpha }\end{array}$ & $\begin{array}{l}\text { MST eccentricity } \\
\text { Upper alpha }\end{array}$ & $\begin{array}{l}\text { MST BC } \\
\text { Upper alpha }\end{array}$ & $\begin{array}{l}\text { MST T }_{H} \\
\text { Upper alpha }\end{array}$ \\
\hline Working memory & $\begin{array}{l}\mathrm{r}=0.063^{\mathrm{a}} \\
p=0.697\end{array}$ & $\begin{array}{l}\mathrm{r}=0.211^{\mathrm{a}} \\
p=0.194\end{array}$ & $\begin{array}{l}\mathrm{r}=0.189^{\mathrm{a}} \\
p=0.243\end{array}$ & $\begin{array}{l}\mathrm{r}=0.123^{\mathrm{a}} \\
p=0.454\end{array}$ & $\begin{array}{l}\mathrm{r}=0.069^{\mathrm{a}} \\
p=0.673\end{array}$ & $\begin{array}{l}\mathrm{r}=0.076^{\mathrm{a}} \\
p=0.647\end{array}$ & $\begin{array}{l}\mathrm{r}=-.090^{\mathrm{a}} \\
p=0.581\end{array}$ & $\begin{array}{l}\mathrm{r}=0.032^{\mathrm{a}} \\
p=0.845\end{array}$ \\
\hline
\end{tabular}

$P L I$ Phase Lag Index, DMN default mode network, $F P L$ fronto parietal network left, $F P R$ fronto parietal network right, $M S T$ minimum spanning tree, $B C$ betweenness centrality, $T_{H}$ hierarchy

Correlation is significant at the $p<0.05$ level

aNonparametric correlation, Kendall's tau_b test, $r=$ correlation coefficient

Table 4 Correlations between cognitive functioning and functional connectivity of the global network

\begin{tabular}{llll}
\hline Cognitive domain & $\begin{array}{l}\text { PLI mean } \\
\text { Theta band }\end{array}$ & $\begin{array}{l}\text { PLI mean } \\
\text { Lower alpha band }\end{array}$ & $\begin{array}{l}\text { PLI mean } \\
\text { Upper alpha band }\end{array}$ \\
\hline Executive functioning & $\mathrm{r}=-0.330^{\mathrm{a}}$ & $\mathrm{r}=-0.281^{\mathrm{a}}$ & $\mathrm{r}=-0.131^{\mathrm{a}}$ \\
& $p=0.058$ & $p=0.103$ & $p=0.448$ \\
Psychomotor speed & $\mathrm{r}=-0.037^{\mathrm{a}}$ & $\mathrm{r}=-0.242^{\mathrm{a}}$ & $\mathrm{r}=-0.053^{\mathrm{a}}$ \\
& $p=0.820$ & $p=0.136$ & $p=0.745$ \\
Working memory & $\mathrm{r}=-0.005^{\mathrm{a}}$ & $\mathrm{r}=0.126^{\mathrm{a}}$ & $\mathrm{r}=-0.063^{\mathrm{a}}$ \\
& $p=0.974$ & $p=0.436$ & $p=0.697$ \\
Information processing & $\mathrm{r}=-.0 .106^{\mathrm{a}}$ & $\mathrm{r}=-0.195^{\mathrm{a}}$ & $\mathrm{r}=.0 .016^{\mathrm{a}}$ \\
& $p=0.516$ & $p=0.230$ & $p=0.922$ \\
Attention & $\mathrm{r}=-0.040^{\mathrm{a}}$ & $\mathrm{r}=-0.124^{\mathrm{a}}$ & $\mathrm{r}=-0.236^{\mathrm{a}}$ \\
& $p=0.820$ & $p=0.472$ & $p=0.172$ \\
Verbal memory & $\mathrm{r}=-0.177^{\mathrm{a}}$ & $\mathrm{r}=-0.310^{\mathrm{a}}$ & $\mathrm{r}=-0.171^{\mathrm{a}}$ \\
& $p=0.293$ & $p=0.064$ & $p=0.310$ \\
\hline
\end{tabular}

PLI Phase Lag Index

Correlation is significant at the $p<0.05$ level

${ }^{a}$ Nonparametric correlation, Kendall's tau_b test, $r=$ correlation coefficient glioma patients [9-11, 36]. Bosma et al. found a large number of significant, both positive and negative, correlations between short-distance and interhemispheric functional connectivity (PLI) and cognitive performance in low-grade glioma patients [10]. Hu et al. reported positive correlations between cognition and "small world" characteristics in the alpha and high gamma band in glioma patients [36]. It is not known whether these conflicting results are due to the differences in methodology (source space versus sensor space; average functional connectivity versus RSN connectivity) or due to differences between tumor types.

Previous work has revealed that global alterations in connectivity can occur in the presence of a lesion, including in regions in the contralateral hemisphere [7, 37].
Moreover, the impact of lesions in an anatomically realistic model of the human brain relies to a large extent on the importance, or 'hub' status, of the lesioned area in the anatomical network [37, 38]. A previous fMRI study on DMN connectivity in glioma patients showed significant differences in DMN connectivity when comparing tumors located within the anterior cingulate cortex and the left lateral parietal cortex, suggesting that the location of the tumor is important for the extent to which the DMN connectivity is affected [39]. However, post-hoc analyses of our data did not reveal significant differences in cognition or RSN connectivity between the patients with frontal (60\%, see Table S1) and non-frontal meningiomas (40\%). An explanation for the difference between our results and 
those by Harris and colleagues could be that intra-axial, infiltratively growing gliomas might influence DMN connectivity in a different way than extra-axial located meningiomas [11].

Prior to the present study, no studies had been performed on MST in WHO grade I meningioma patients. MST analysis captures important information about the topology of the full network [40]. Previous MEG studies in patients with Parkinson's disease and in patients with multiple sclerosis using MST demonstrated changes in MST metrics in the alpha 1 and alpha 2 band which were associated with poorer cognitive performance $[23,24]$. The conclusions from these studies are that lower cognitive performance related to a more line-like ("less integrated") network configuration. The MST findings of the present study are therefore loosely consistent with these previous results.

A number of limitations of this study should be mentioned. First of all, a causal relation of the association between functional connectivity of the DMN and topology of functional networks on the one hand and working memory on the other hand, remains unclear because of the cross-sectional nature of this study and the lack of MEG recordings in a control group. The aim of our study, however, was not to assess causality nor to compare meningioma patients and healthy controls, but to investigate the correlation between functional RSN connectivity and topology of functional networks on the one hand and cognitive functioning on the other hand within a group of WHO grade I meningioma patients. Secondly, as part of our analysis approach we normalized the patients' MRIs to a template brain (and then labelled voxels using a standard (AAL) atlas), while our patients had altered anatomy due to the tumor, and this discrepancy might have influenced our results. Thirdly, since a preoperative cognitive assessment and MEG recordings were lacking, differentiation between tumor and treatment related factors and their effect on cognition, functional connectivity and functional network topology could not be established, hampering the understanding of the pathophysiology of cognitive deficits and possible changes in functional connectivity and functional network topology in meningioma patients during the disease course. Finally, due to the small number of patients in this study, we did not apply statistical corrections for the number of tests (one for each resting-state network and MST measure the different frequency band). For the same reason, the role of tumor location on cognitive functioning was not studied. Our study is the first, exploratory study on functional connectivity in WHO grade I meningioma patients, and corrections for multiple testing would have reduced power and increased Type II errors, thereby hindering advances in the field. We focused on interpreting general patterns of the findings instead, but we report exact $\mathrm{P}$-values of all individual statistical comparisons for ease of survey.
In conclusion, significant correlations were found between working memory deficits and decreased functional connectivity in the default-mode network, and with hub-pathology. Future studies are needed to further investigate the pathophysiology of cognitive deficits and possible changes in functional connectivity and function network topology in meningioma patients during the disease course and due to treatment. Better understanding of the pathophysiology of cognitive deficits may be helpful in determining the clinical value and optimal timing of treatment of meningioma patients.

Acknowledgements The authors would like to thank N. Sijsma for her assistance with data analysis; P. Tewarie and K. Olde Dubbelink for their input on the definition of resting-state networks; and the MEG technicians of the Department of Clinical Neurophysiology, P.J. Ris, N. Sijsma and K. Plugge, for technical assistance. L. Douw was supported by a Veni grant of the Netherlands Organisation for Scientific Research (NWO) and the Branco Weiss Fellowship (Society in Science). Scanning costs were partially funded by the Amsterdam Brain Imaging Platform (ABIP), Amsterdam, The Netherlands.

\section{Compliance with ethical standards}

Conflict of interest The authors declare that they have no conflict of interest.

Open Access This article is distributed under the terms of the Creative Commons Attribution 4.0 International License (http://creativeco mmons.org/licenses/by/4.0/), which permits unrestricted use, distribution, and reproduction in any medium, provided you give appropriate credit to the original author(s) and the source, provide a link to the Creative Commons license, and indicate if changes were made.

\section{Appendix 1: Description of the neuropsychological test battery}

\section{Test domains}

\section{Overall cognitive performance Intelligence}

The Dutch Adult Reading Test (DART) [41] The Dutch version of the New Adult Reading Test provides a measure of premorbid capacity based on verbal ability.

\section{Perception}

Line Bisection Test [42] This test is a device for measuring unilateral neglect, which is usually a sequel of massive right hemisphere lesions. Noticeable errors are most often made by patients with visual field defects who tend to underestimate the side of the line opposite to the defective field. Outcome measures are horizontal and vertical deviations. 


\section{Memory}

Auditory Verbal Learning Test (AVLT) [43] This version of the Rey Auditory Verbal Learning Test calls for various aspects of verbal learning and recall. Measures used for analysis are: memory performance on trial 1 as indicator of immediate recall, total recall after five trials, delayed recall and recognition after $20 \mathrm{~min}$ as indicators of memory consolidation into long-term memory, and a delta score as a measure of learning capacity.

Working Memory Task (WMT) [44] This task is designed to measure the speed of memory processes. The underlying principle is that the extra time needed to complete a test in which there is a stepwise increase in the amount of information to be kept in memory, is a measure of the ease at which information is processed in working memory. Capacity is measured by using the slope and intercept as a function of the number of letters to be kept in working memory.

\section{Attention and executive function}

Stroop Color-Word Test (SCWT) [43] This test is a selective attention task aiming at measuring interference susceptibility and consists of three subtasks with increasing task complexity.

Categoric Word Fluency [45] This is a task requiring the generation of words from specific semantic categories (animals) within a limited time.

Concept Shifting Test (CST) [46] This test, which has two conditions of complexity, predominantly measures functions associated with executive function, especially visual scanning and conceptual tracking. The motor component of this task is measured by three dummy conditions in which no neurocognitive capacity except for graphomotor speed is required.

\section{Speed}

Letter-Digit Substitutiuon Test (LDST) [47] This test, measures psychomotor speed that is relatively unaffected by a decline in intellectual ability. Participants are required to replace the randomized letters with the appropriate digit indicated by the key, as quickly as possible.

\section{References}

1. Saraf S, McCarthy BJ, Villano JL (2011) Update on meningiomas. Oncologist 16(11):1604-1613. https://doi.org/10.1634/theoncolog ist.2011-0193

2. Meskal I, Gehring K, Rutten GJ, Sitskoorn MM (2016) Cognitive functioning in meningioma patients: a systematic review. J Neuro-Oncol 128(2):195-205. https://doi.org/10.1007/s1106 $0-016-2115-\mathrm{z}$

3. Derks J, Reijneveld JC, Douw L (2014) Neural network alterations underlie cognitive deficits in brain tumor patients. Curr Opin Oncol 26(6):627-633. https://doi.org/10.1097/cco.0000000000 000126

4. Bullmore E, Sporns O (2012) The economy of brain network organization. Nat Rev Neurosci 13(5):336-349. https://doi. org/10.1038/nrn3214

5. Stam CJ (2014) Modern network science of neurological disorders. Nat Rev Neurosci 15(10):683-695. https://doi.org/10.1038/ nrn3801

6. Bartolomei F, Bosma I, Klein M, Baayen JC, Reijneveld JC, Postma TJ, Heimans JJ, van Dijk BW, de Munck JC, de Jongh A, Cover KS, Stam CJ (2006) Disturbed functional connectivity in brain tumour patients: evaluation by graph analysis of synchronization matrices. Clin Neurophysiol 117(9):2039-2049. https:// doi.org/10.1016/j.clinph.2006.05.018

7. Bartolomei F, Bosma I, Klein M, Baayen JC, Reijneveld JC, Postma TJ, Heimans JJ, van Dijk BW, de Munck JC, de Jongh A, Cover KS, Stam CJ (2006) How do brain tumors alter functional connectivity? A magnetoencephalography study. Ann Neurol 59(1):128-138. https://doi.org/10.1002/ana.20710

8. van Dellen E, de Witt Hamer PC, Douw L, Klein M, Heimans JJ, Stam CJ, Reijneveld JC, Hillebrand A (2012) Connectivity in MEG resting-state networks increases after resective surgery for low-grade glioma and correlates with improved cognitive performance. Neuroimage 2:1-7. https://doi.org/10.1016/j. nicl.2012.10.007

9. van Dellen E, Douw L, Hillebrand A, Ris-Hilgersom IH, Schoonheim MM, Baayen JC, De Witt Hamer PC, Velis DN, Klein M, Heimans JJ, Stam CJ, Reijneveld JC (2012) MEG network differences between low- and high-grade glioma related to epilepsy and cognition. PLoS ONE 7(11):e50122. https://doi.org/10.1371/journ al.pone.0050122

10. Bosma I, Stam CJ, Douw L, Bartolomei F, Heimans JJ, van Dijk BW, Postma TJ, Klein M, Reijneveld JC (2008) The influence of low-grade glioma on resting state oscillatory brain activity: a magnetoencephalography study. J Neuro-Oncol 88(1):77-85. https ://doi.org/10.1007/s11060-008-9535-3

11. Bosma I, Reijneveld JC, Klein M, Douw L, van Dijk BW, Heimans JJ, Stam CJ (2009) Disturbed functional brain networks and neurocognitive function in low-grade glioma patients: a graph theoretical analysis of resting-state MEG. Nonlinear Biomed Phys 3(1):9. https://doi.org/10.1186/1753-4631-3-9

12. Douw L, Baayen H, Bosma I, Klein M, Vandertop P, Heimans J, Stam K, de Munck J, Reijneveld J (2008) Treatment-related changes in functional connectivity in brain tumor patients: a magnetoencephalography study. Exp Neurol 212(2):285-290. https:// doi.org/10.1016/j.expneurol.2008.03.013

13. Crossley NA, Mechelli A, Scott J, Carletti F, Fox PT, McGuire P, Bullmore ET (2014) The hubs of the human connectome are generally implicated in the anatomy of brain disorders. Brain $137(\mathrm{Pt}$ 8):2382-2395. https://doi.org/10.1093/brain/awu132

14. van den Heuvel MP, Hulshoff Pol HE (2010) Exploring the brain network: a review on resting-state fMRI functional connectivity. Eur Neuropsychopharmacol 20(8):519-534. https://doi. org/10.1016/j.euroneuro.2010.03.008 
15. Rosazza C, Minati L (2011) Resting-state brain networks: literature review and clinical applications. Neurol Sci 32(5):773-785. https://doi.org/10.1007/s10072-011-0636-y

16. Broyd SJ, Demanuele C, Debener S, Helps SK, James CJ, SonugaBarke EJ (2009) Default-mode brain dysfunction in mental disorders: a systematic review. Neurosci Biobehav Rev 33(3):279-296. https://doi.org/10.1016/j.neubiorev.2008.09.002

17. Damoiseaux JS, Beckmann CF, Arigita EJ, Barkhof F, Scheltens P, Stam CJ, Smith SM, Rombouts SA (2008) Reduced restingstate brain activity in the "default network" in normal aging. Cereb Cortex (New York: 1991) 18(8):1856-1864. https://doi. org/10.1093/cercor/bhm207

18. Nomura EM, Gratton C, Visser RM, Kayser A, Perez F, D'Esposito M (2010) Double dissociation of two cognitive control networks in patients with focal brain lesions. Proc Natl Acad Sci USA 107(26):12017-12022. https://doi.org/10.1073/pnas.10024 31107

19. Baillet S (2017) Magnetoencephalography for brain electrophysiology and imaging. Nat Neurosci 20(3):327-339. https://doi. org/10.1038/nn.4504

20. Brookes MJ, Woolrich M, Luckhoo H, Price D, Hale JR, Stephenson MC, Barnes GR, Smith SM, Morris PG (2011) Investigating the electrophysiological basis of resting state networks using magnetoencephalography. Proc Natl Acad Sci USA 108(40):1678316788. https://doi.org/10.1073/pnas. 1112685108

21. van Wijk BC, Stam CJ, Daffertshofer A (2010) Comparing brain networks of different size and connectivity density using graph theory. PLoS ONE 5(10):e13701. https://doi.org/10.1371/journ al.pone.0013701

22. Stam CJ, Tewarie P, Van Dellen E, van Straaten EC, Hillebrand A, Van Mieghem P (2014) The trees and the forest: Characterization of complex brain networks with minimum spanning trees. Int J Psychophysiol 92(3):129-138. https://doi.org/10.1016/j.ijpsy cho.2014.04.001

23. Tewarie P, Hillebrand A, Schoonheim MM, van Dijk BW, Geurts JJ, Barkhof F, Polman CH, Stam CJ (2014) Functional brain network analysis using minimum spanning trees in Multiple Sclerosis: an MEG source-space study. NeuroImage 88:308-318. https ://doi.org/10.1016/j.neuroimage.2013.10.022

24. Olde Dubbelink KT, Hillebrand A, Stoffers D, Deijen JB, Twisk JW, Stam CJ, Berendse HW (2014) Disrupted brain network topology in Parkinson's disease: a longitudinal magnetoencephalography study. Brain 137(Pt 1):197-207. https://doi.org/10.1093/ brain/awt316

25. Jolles J, van Boxtel MP, Ponds RW, Metsemakers JF, Houx PJ (1998) The Maastricht aging study (MAAS). The longitudinal perspective of cognitive aging. Tijdschrift voor gerontologie en geriatrie 29(3):120-129

26. de Bie S (1987) Standard questions 1987: proposal for uniformization of questions regarding background variables and interviews [Standaardvragen 1987: Voorstellen voor uniformering van vraagstellingen naar achtergrondkenmerken en interviews]. Leiden University Press, Leiden, p 2

27. Klein M, Engelberts NH, van der Ploeg HM, Kasteleijn-Nolst Trenite DG, Aaronson NK, Taphoorn MJ, Baaijen H, Vandertop WP, Muller M, Postma TJ, Heimans JJ (2003) Epilepsy in low-grade gliomas: the impact on cognitive function and quality of life. Ann Neurol 54(4):514-520. https://doi.org/10.1002/ ana.10712

28. Winocur G, Hasher L (2004) Age and time-of-day effects on learning and memory in a non-matching-to-sample test. Neurobiol Aging 25(8):1107-1115. https://doi.org/10.1016/j.neurobiola ging.2003.10.005

29. Robinson SVJ (1999) Functional neuroimaging by synthetic aperture magnetometry (SAM). In: Recent advances in biomagnetism. Tohoku University Press, Sendai
30. Huang MX, Mosher JC, Leahy RM (1999) A sensor-weighted overlapping-sphere head model and exhaustive head model comparison for MEG. Phys Med Biol 44(2):423-440

31. Hillebrand A, Barnes GR, Bosboom JL, Berendse HW, Stam CJ (2012) Frequency-dependent functional connectivity within resting-state networks: an atlas-based MEG beamformer solution. NeuroImage 59(4):3909-3921. https://doi.org/10.1016/j.neuro image.2011.11.005

32. Stam CJ, Nolte G, Daffertshofer A (2007) Phase lag index: assessment of functional connectivity from multi channel EEG and MEG with diminished bias from common sources. Hum Brain Mapp 28(11):1178-1193. https://doi.org/10.1002/hbm.20346

33. Kruskal J (1956) On the shortest spanning subtree of a graph and the traveling salesman problem. Proc Am Math Soc 7:48-50

34. Boersma M, Smit DJ, Boomsma DI, De Geus EJ, Delemarre-van de Waal HA, Stam CJ (2013) Growing trees in child brains: graph theoretical analysis of electroencephalography-derived minimum spanning tree in 5- and 7-year-old children reflects brain maturation. Brain Connect 3(1):50-60. https://doi.org/10.1089/brain .2012.0106

35. Toth B, Kardos Z, File B, Boha R, Stam CJ, Molnar M (2014) Frontal midline theta connectivity is related to efficiency of WM maintenance and is affected by aging. Neurobiol Learn Mem 114:58-69. https://doi.org/10.1016/j.nlm.2014.04.009

36. Hu XH, Lei T, Xu HZ, Zou YJ, Liu HY (2013) Resting-state magnetoencephalography study of "small world" characteristics and cognitive dysfunction in patients with glioma. Onco Targets Therapy 6:311-313. https://doi.org/10.2147/ott.s42471

37. van Dellen E, Hillebrand A, Douw L, Heimans JJ, Reijneveld JC, Stam CJ (2013) Local polymorphic delta activity in cortical lesions causes global decreases in functional connectivity. NeuroImage 83:524-532. https://doi.org/10.1016/j.neuroimage 2013.06.009

38. Alstott J, Breakspear M, Hagmann P, Cammoun L, Sporns O (2009) Modeling the impact of lesions in the human brain. PLoS Comput Biol 5(6):e1000408. https://doi.org/10.1371/journ al.pcbi.1000408

39. Harris RJ, Bookheimer SY, Cloughesy TF, Kim HJ, Pope WB, Lai A, Nghiemphu PL, Liau LM, Ellingson BM (2014) Altered functional connectivity of the default mode network in diffuse gliomas measured with pseudo-resting state fMRI. J Neuro-Oncol 116(2):373-379. https://doi.org/10.1007/s11060-013-1304-2

40. Tewarie P, van Dellen E, Hillebrand A, Stam CJ (2015) The minimum spanning tree: an unbiased method for brain network analysis. NeuroImage 104:177-188. https://doi.org/10.1016/j.neuro image.2014.10.015

41. Schmand B, Bakker D, Saan R, Louman J (1991) The dutch reading test for adults: a measure of premorbid intelligence level. Tijdschr Gerontol Geriatr 22(1):15-19

42. Schenkenberg T, Bradford DC, Ajax ET (1980) Line bisection and unilateral visual neglect in patients with neurologic impairment. Neurology 30:509-517

43. Lezak MD (2004) Neuropsychological assessment, 4th edn. Oxford University Press, New York

44. Sternberg S (1975) Memory scanning: new findings and current controversies. Q J Exp Psychol 27:1-32

45. Benton AL (1968) Differential behavioral effects in frontal lobe disease. Neuropsychologia 6:53-60

46. Houx PJ, Jolles J (1994) Vulnerability factors for age-related cognitive decline. In: Isaacson RL, Jensen KF (eds) The vulnerable brain and environmental risks. Plenum Press, New York, pp 25-41

47. Jolles J, Houx PJ, van Boxtel MPJ, Ponds RWHM (1995) Maastricht Aging Study: determinants of cognitive aging. Neuropsych Publishers, Maastricht 